\title{
ELETROQUIMIOTERAPIA COMO TRATAMENTO DE CARCINOMA ESPINOCELULAR EM FELINO: RELATO DE CASO
}

Katyani Scheffer Spelfer ${ }^{1}$ Camila Neri Barra ${ }^{2}$

SPELFER, K. S.; BARRA, C. N. Eletroquimioterapia como tratamento de carcinoma espinocelular em felino: relato de caso. Arquivos de Ciências Veterinárias e Zoologia da UNIPAR, Umuarama, v. 23, n. 2cont., e2304, 2020.

RESUMO: O carcinoma de células escamosas (CCE) é uma neoplasia maligna resultante da diferenciação de ceratinócitos, que acomete principalmente animais de pelagem clara e pouco pigmentados, decorrente da exposição à radiação ultravioleta. Apresentam evolução lenta e baixo caráter metastático, porém, em alguns mais avançados pode ocorrer acometimento metastático de órgãos adjacentes. Os tratamentos utilizados no CCE incluem cirurgia, radioterapia, quimioterapia, crioterapia e eletroquimioterapia (EQT). A eletroquimioterapia se mostra bastante eficaz no tratamento desse tumor, dentre outros e comumente não apresenta efeito colateral. O presente trabalho tem como objetivo relatar o caso de um felino atendido na Clínica Veterinária Bichos S.A. no município de Foz do Iguaçu, diagnosticado com Carcinoma de Células Escamosas e portador do vírus da imunodefiência felina. $\mathrm{O}$ tratamento adotado para a neoplasia foi a eletroquimioterapia, resultando em remissão parcial das lesões, após vinte dias da EQT. Com objetivo de investigar possível acometimento ósseo, foi realizada radiografia de face, onde a mesma apresentou área de lise óssea em arco zigomático e maxila esquerda, indicativo de infiltração neoplásica. A radiografia torácica apontou presença de área nodular sobrepondo lobo pulmonar caudal direito, indicativo de processo metastático. Em virtude do prognóstico reservado, os tutores optaram pela eutanásia do mesmo.

PALAVRAS-CHAVE: Carcinoma espinocelular. Eletroporação. Felino doméstico.

\section{ELECTROCHEMOTHERAPY AS TREATMENT OF SQUAMOUS CELL CARCINOMA IN FELINE: CASE REPORT}

\begin{abstract}
Squamous cell carcinoma (SCC) is a malignant neoplasm resulting from the differentiation of keratinocytes, which mainly affects light-colored and non-pigmented animals due to exposure to ultraviolet radiation. Although they present slow evolution and low metastatic character, in some more advanced cases, metastatic involvement of adjacent organs may occur. The treatments used in SCC include surgery, radiotherapy, chemotherapy, cryotherapy and electrochemotherapy (ECT). Electrochemotherapy is quite effective in the treatment of this type of tumor, among others, and it usually has no side effect. This work aims at reporting the case of a feline treated at the Veterinary Clinic Bichos S.A. in the city of Foz do Iguaçu diagnosed with Squamous Cell Carcinoma and carrying the feline immunodefense virus (FIV). Electrochemotherapy was the treatment of choice for the neoplasia, resulting in partial remission of the lesions after twenty days of treatment. In order to investigate possible bone involvement, an X-ray of the face was performed, where it presented area of bone lysis in the zygomatic arch and left maxilla, signs of neoplastic infiltration. The chest X-ray showed a nodular area overlapping the right caudal pulmonary lobe, an indication of metastatic process. Due to the reserved prognosis, the tutors chose euthanasia of the subject.
\end{abstract}

KEYWORDS: Domestic feline. Electrochemotherapy. Squamous cell carcinoma.

\section{ELECTROQUIMIOTERAPIA COMO TRATAMIENTO DEL CARCINOMA DE CÉLULAS ESCAMOSAS EN FELINO: RELATO DE CASO}

RESUMEN: El carcinoma de células escamosas (CEC) es una neoplasia maligna resultante de la diferenciación de queratinocitos, que afecta principalmente a animales de pelaje claro y de poca pigmentación, resultado de la exposición a la radiación ultravioleta. Tienen una evolución lenta y un carácter metastásico bajo, sin embargo, en algunos más avanzados puede producirse afectación metastásica de órganos adyacentes. Los tratamientos utilizados en el CEC incluyen cirugía, radioterapia, quimioterapia, crioterapia y electroquimioterapia (EQT). La electroquimioterapia es muy eficaz en el tratamiento de ese tumor, entre otros y no suele tener efectos secundarios. Este trabajo tiene como objetivo reportar el caso de un felino atendido en la Clínica Veterinária Bichos S.A. de la ciudad de Foz do Iguaçu, diagnosticado con Carcinoma de Células Escamosas y con el virus de la inmunodeficiencia felina. El tratamiento adoptado para la neoplasia fue la electroquimioterapia, resultando en remisión parcial de las lesiones luego de veinte días de EQT. Con el fin de investigar la posible afectación ósea se realizó una radiografía de rostro, donde se presentó un área de lisis ósea en arco cigomático y maxilar izquierdo, indicativo de infiltración neoplásica. La radiografía de tórax mostró la presencia de un área nodular superpuesta al lóbulo pulmonar caudal derecho, lo que indicaba un proceso metastásico. Debido al pronóstico reservado, los tutores optaron por la eutanasia. PALABRAS CLAVE: Carcinoma de células escamosas, Electroporación, Felino doméstico.

DOI: 10.25110 /arqvet.v23i2cont.2020.7095

${ }^{1}$ Médica Veterinária pela Universidade Centro Universitário Dinâmica das Cataratas (UDC - PR/Brasil). katyani.spelfer@gmail.com

${ }^{2}$ Médica Veterinária pela Universidade de Uberaba, MG. Mestre em Ciências pelo Departamento de Patologia Veterinária da Faculdade de Medicina Veterinária e Zootecnia da Universidade de São Paulo (FMVZ-USP-SP). camilaneribarra@gmail.com 


\section{Introdução}

Para Daleck e De Nardi (2016) o carcinoma de células escamosas (CCE) ou carcinoma espinocelular (CEC) é uma neoplasia cutânea maligna que têm sua origem no epitélio escamoso estratificado escamoso e representa $15 \%$ dos tumores cutâneos em felinos. Sua etiologia está relacionada à exposição crônica à radiação solar. Segundo os mesmos autores em felinos o CCE não possui distinção de sexo, tampouco raça, entretanto, acomete comumente animais entre nove a catorze anos de vida, principalmente os que possuem pelagem clara ou despigmentada. Em cães varia entre os seis a dez anos, com maior risco de acometimento nas raças Keeshound, Schnauzer, Basset hound, Collie, Dálmata, Pitbull Terrier e Beagle.

As lesões caracterizam-se como múltiplas ou únicas, geralmente ulceradas, crostosas recobertas, ou pode manifestar como lesão nodular proliferativa, preferencialmente em pavilhão auricular, plano nasal, pálpebras, cabeça e regiões despigmentadas, sendo os tumores localizados em plano nasal são lesões de caráter mais agressivo que desenvolvem rapidamente (THOMSON, 2007).

Metástases são incomuns, entretanto, quando ocorrem, acomete linfonodos regionais e pulmões, geralmente acarretando invasão para tecidos adjacentes e dependendo da localização anatômica pode levar a infiltração óssea (MURPHY, 2013). A forma de estadiamento clínico para CEC felino segue o padrão do sistema TNM (tumor/linfonodo/metástase) (WITHROW; VAIL, 2007), onde é avaliado o tamanho tumoral, acometimento nodal e apresentação de metástase distante ou não.

O diagnóstico de triagem é realizado por meio de citologia por agulha fina, entretanto, faz-se necessária confirmação diagnóstica por meio de biópsia e análise histopatológica (DALECK; DE NARDI, 2016).

Os tratamentos mais efetivos para o CEC incluem cirurgia, sendo o de eleição, entretanto, a radioterapia, quimioterapia, crioterapia e eletroquimioterapia também podem ser empregados. Em alguns casos, dependendo da localização, acometimento tumoral ou em casos de neoplasias inoperáveis utiliza-se terapias que visam melhorar a sobrevida do paciente (CEMAZAR et al., 2008). Neste contexto, destaca-se a eletroquimioterapia (EQT), que apresenta eficácia no tratamento antineoplásico em sarcomas, gliomas, carcinomas e melanomas, e contrário a isso nas neoplasias de origem óssea e hematopoiética (GIARDINO et al., 2006).

A EQT tem como objetivo aumentar a permeabilidade da membrana das células e potencializar a entrada, aumentando a eficácia dos quimioterápicos no interior das células neoplásicas (CIRIA; LÓPEZ, 2001; OLIVEIRA et al., 2009).

Nessa terapia utilizam-se fármacos como a bleomicina (BLM) em associação com os pulsos elétricos disparados por eletrodos, os quais irão potencializar a citotoxicidade dos fármacos (OLIVEIRA et al., 2009). A permeabilização transitória das células é conhecida como eletropermeabilização ou eletroporação. A mesma decorre da aplicação de pulsos elétricos de alta voltagem, aumentando assim, o potencial de transporte da membrana celular o que resulta na redução do fluxo sanguíneo tumoral, o que irá promover hipóxia e maior acidez no meio extracelular, levando à necrose da massa tumoral (UGEN et al., 2003).

Com o objetivo de elucidar as causas, complicações e formas de tratamento do carcinoma de células escamosas ou carcinoma espinocelular felino (CCE), foi relatado um caso clínico para descrever a abordagem terapêutica mediante acompanhamento do paciente acometido pela doença.

\section{Relato de caso}

Foi atendido em maio de 2017 na Clínica Veterinária Bichos S.A., no município de Foz do Iguaçu - PR, um felino, macho, Siamês, de 12 anos de idade. Animal de vida livre, portador de Imunodeficiência felina (FIV), apresentando múltiplas lesões na região periocular, cervical e torácica de aspecto circular e ulcerada na pálpebra superior direita.

O tratamento preconizado foi somente cirúrgico, como exérese da lesão e a mesma encaminhada para análise histopatológica com o diagnóstico de Carcinoma Espinocelular bem diferenciado.

Figura 1: Gato macho, Siamês de 12 anos de idade, com lesão periocular de aspecto circular, ulcerada, crostosa e exsudativa. Foz do Iguaçu, PR, 2017.

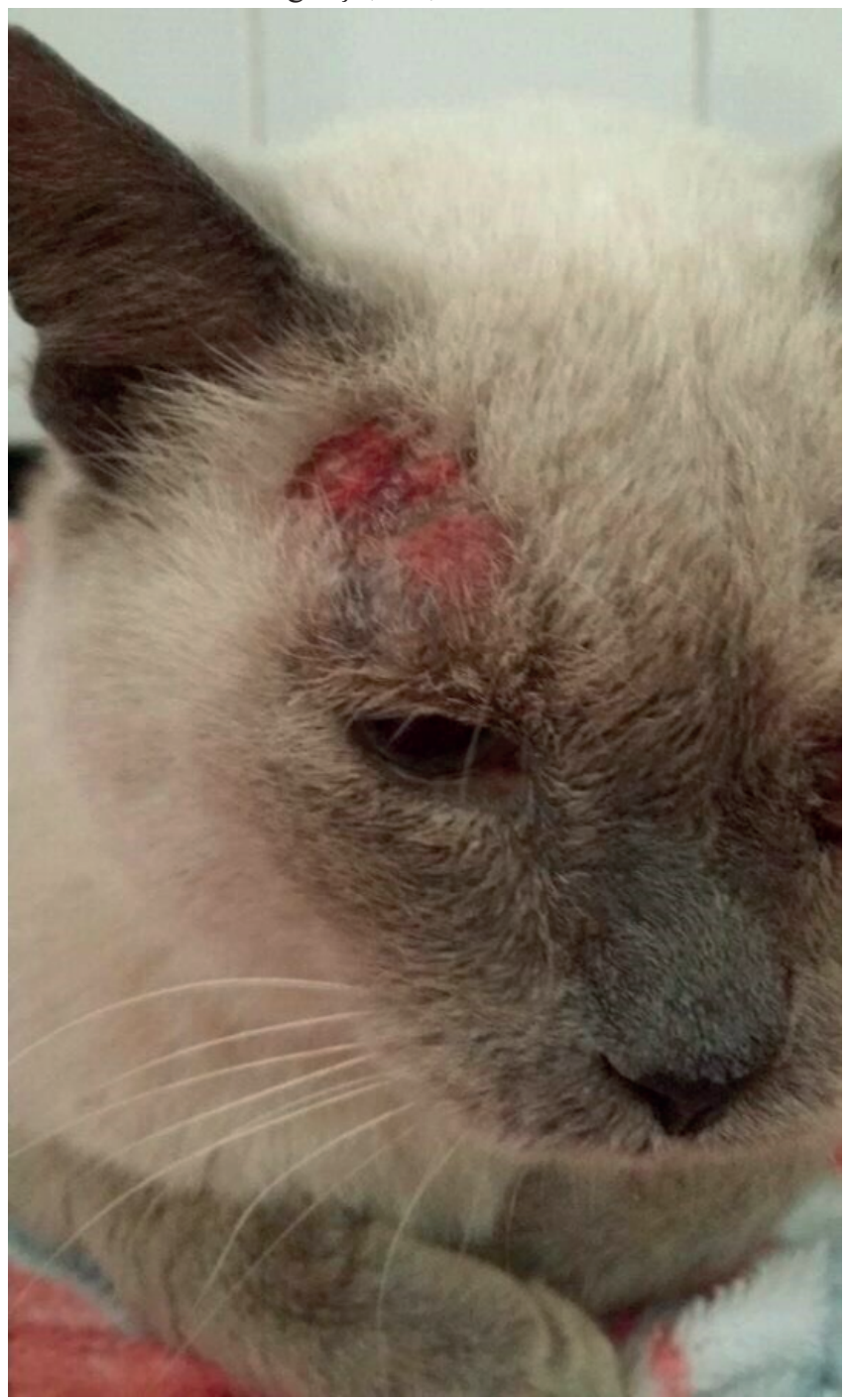

Fonte: arquivo pessoal. 
No dia 28 de março de 2018 o animal retornou a clínica apresentando lesões ulceradas, crostosas com presença de exsudato purulento, uveíte, quemose, eritema, blefatoespasmo e edema na região da exérese cirúrgica. No exame clínico o paciente apresentou normorexia, normodipsia e normoquesia. Avaliação de hemograma e bioquímicos estavam dentro dos padrões de normalidade. Ainda, foi solicitada a citologia por agulha fina na lesão a qual confirmou a recidiva do CEC.

Figura 2: Retorno do paciente realizada no dia 28 de março, 2018. Lesão na região periocular com aspecto nodular, ulcerada, crostosa, e exsudativa. Presença de uveíte, quemose e edema. Foz do Iguaçu, PR, 2017.

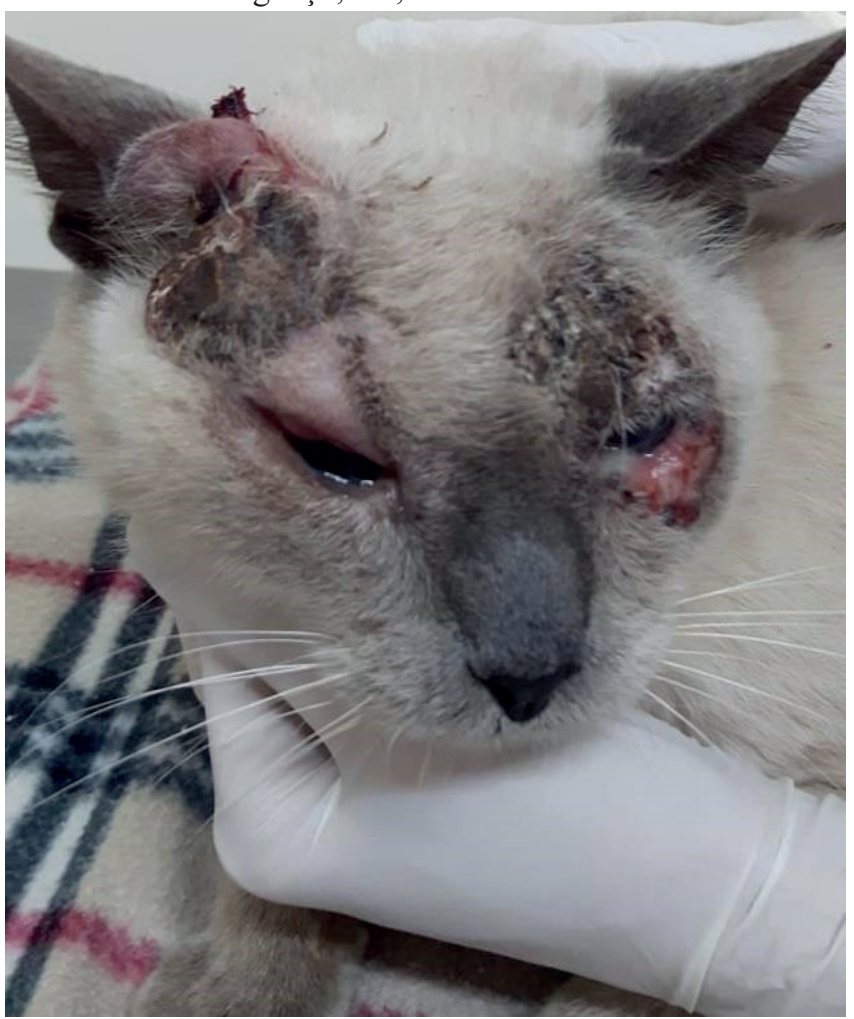

Fonte: arquivo pessoal.

Em decorrência da apresentação multifocal das lesões optou-se pelo tratamento de EQT realizada no dia 5 de abril de 2018, associado à quimioterapia adjuvante. A mesma foi efetivada com o paciente induzido, seguido de MPA (anestesia pré-operatória), anestesia intravenosa e manutenção com inalatória.

Para o procedimento utilizou-se o sulfato de bleomicina por via intravenosa, na dose $15 \mathrm{U} / \mathrm{m}^{2}$. Após cinco minutos decorrente da aplicação do fármaco, pulsos elétricos com tensão de $1000 \mathrm{~V}$ foram aplicadas nas lesões, em onda quadrada unipolar, com duração de 100 microssegundos, concluindo um total de oito ciclos, gerados com um Eletroporador (Crown Modelo BK100 Cromática Ltda.) que dispõe de seis agulhas de aço inoxidável.

Após a EQT, o animal retornou no dia 27 de abril com regressão parcial das lesões nas duas primeiras semanas, diminuição da inflamação e redução das terceiras pálpebras. Parâmetros bioquímicos de creatinina, ureia, alaninaminotransferase (ALT) e bilirrubina estavam dentro dos valores de referência. Entretanto, no dia 11 de maio, o animal retornou a clínica com de perda de apetite, hemograma apresentando trombocitopenia, leucocitose com desvio a direita, linfopenia e monocitose. Ureia e ALT dentro dos padrões de referência e aumento de creatinina $(1,95 \mathrm{mg} / \mathrm{dL})$.

Como tratamento foi administrado Enrofloxacino, BID (duas vezes ao dia), via oral por sete dias.

Figura 3: Consulta do dia 27 de abril, 2018. Vinte dias após a eletroquimioterapia (EQT). O animal apresentou regressão parcial das lesões, diminuição da inflamação e redução das terceiras pálpebras.

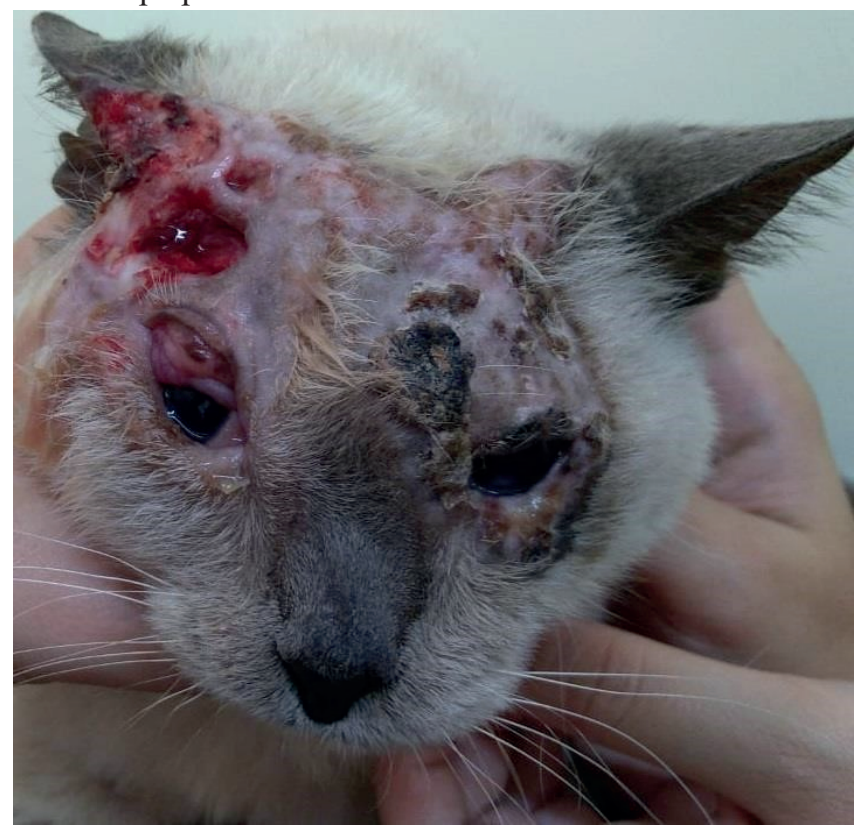

Fonte: arquivo pessoal.

$\mathrm{Na}$ data do retorno do dia 16 de maio, agravou o quadro clínico do paciente e o mesmo manifestava disfagia, apatia, perda de peso e edema facial com exsudato purulento nas lesões. O hemograma apontou diminuição do volume corpuscular médio (VCM) e manteve a leucocitose com desvio à direita e linfopenia. Os parâmetros bioquímicos avaliados foram ALT e Ureia, cujos mesmos não apresentaram alteração, entretanto, houve aumento da creatinina (2,74 mg/ dL) quando comparada ao exame anterior.

Como terapia de suporte foi administrada fluidoterapia com Ringer Lactato durante 24 horas associado o analgésico dipirona sódica, antibiótico enrofloxacino, antiinflamatório meloxicam, antibiótico cefovecina sódica e analgésico cloridrato de tramadol. Em decorrência da intensa inflamação e edema em região infraorbitária, o paciente foi submetido ao procedimento de enucleação do globo ocular direito, entretanto, não houve regressão da inflamação.

Com objetivo de investigar possível acometimento ósseo na área acometida, foi realizada radiografia de face, a qual apresentou extensa área de lise óssea em arco zigomático e maxila esquerda, indicativo de infiltração neoplásica (Figura 4). A radiografia torácica apontou presença de área nodular sobrepondo lobo pulmonar caudal direito, medindo 1,0 centímetro, sendo sugestivo de metástase. Em virtude do quadro clínico do animal e tendo em vista o prognóstico reservado, os tutores optaram pela eutanásia do mesmo. 
Figura 4: Radiografia Facial do paciente. Apresentou extensa área de lise óssea em arco zigomático e maxila esquerda.
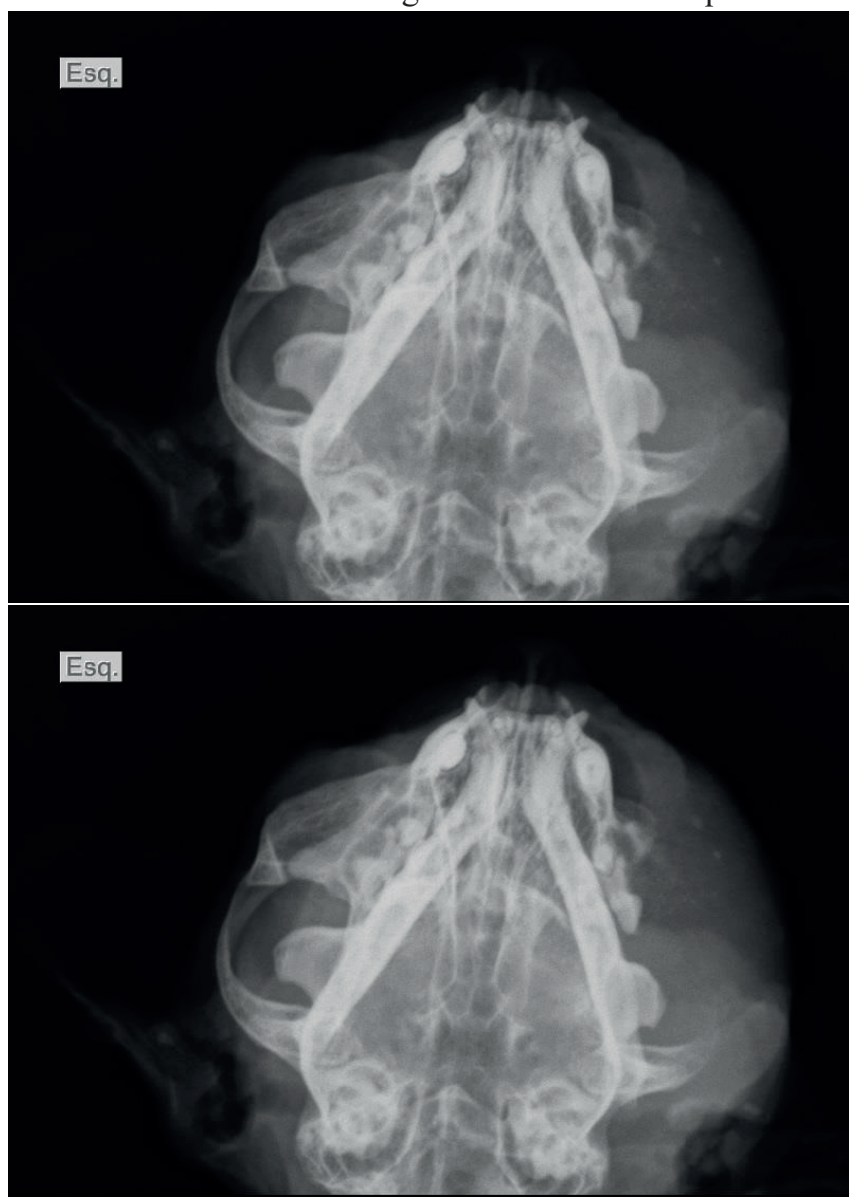

Discussão

De acordo com Daleck e Nardi (2016), o carcinoma de células escamosas em felinos, não apresenta predisposição racial ou de sexo, porém acomete principalmente animais entre nove a catorze anos de vida. Segundo relato apresentado o felino possuía 12 anos quando começou a apresentar as lesões estando dentro da idade relatada por esses autores.

Os tratamentos utilizados para o CEC incluem cirurgia, a radioterapia, quimioterapia, crioterapia e eletroquimioterapia. Essa última se mostra eficiente no tratamento, apresentando poucos efeitos colaterais. Pode ser utilizada como terapia única, em casos de tumores inoperáveis ou quando não é possível ampliar margens cirúrgicas (MARTINS et al., 2015).

Em 21 felinos acometidos por CEC, a eletroquimioterapia realizada com sulfato de bleomicina, demonstrou-se amplamente eficaz na remissão do mesmo, realizado com número de sessões diretamente relacionado ao volume, ao tipo tumoral e ao comportamento biológico da neoplasia abordada (CEMAZAR et al., 2008; GIARDINO et al., 2006; SILVEIRA et al., 2016).

No presente relato, realizou-se o protocolo de EQT como citado no estudo de Silveira et al. (2016), o que resultou em melhora parcial após 20 dias da sessão. Entretanto, com base no estadiamento do CEC, o animal se encontrava em estádio T4 (Tumor invadindo outras estruturas como fáscia, osso ou cartilagem) e M1 (Metástase distante detectada em pulmão) com prognóstico reservado.
Neste contexto, a eletroquimioterapia não demonstra eficácia em neoplasias de origem óssea ou com invasão de tecido ósseo, o que corrobora com o caso descrito onde o paciente se encontrava em estadiamento avançado (GIARDINO et al., 2006)

\section{Conclusão}

O carcinoma de células escamosas ou carcinoma espinocelular é uma neoplasia cutânea maligna, proveniente dos queratinócitos, comumente diagnosticada em felinos. Acomete localizações como pavilhões auriculares, plano nasal, pálpebras, cabeça e regiões despigmentadas. O diagnóstico confirmatório é por meio de biópsia, podendo também, realizar como triagem a citologia por agulha fina.

O tratamento de eleição para o CEC é a cirurgia. Entretanto, a eletroquimioterapia tem sido amplamente utilizada como modalidade terapêutica, associada à cirurgia ou como terapia única. A mesma vem se mostrando eficaz, com respostas satisfatórias e menor índice de recidivas. Todavia, em caso de tumores que acometimento ósseo, a mesma não responde tão bem como nas demais neoplasias, resultando em uma menor sobrevida do animal.

\section{Referências}

CEZAMAR, M. et al. Electrochemotherapy in veterinary oncology. Journal of Veterinary Internal Medicine, v. 22, p. 826-831, 2008.

CIRIA, H. C.; LÓPEZ, D. S. La electroquimioterapia: una nueva alternativa terapêutica en la oncologia. Revista Cubana de Oncologia, v. 17, n. 3, p. 188-194, 2001.

GRANDE, F.; RONDELLI, M. C. H. Neoplasias Cutâneas. In: DALECK, C. R.; DE NARDI, A. B. Oncologia em cães e gatos. $2^{\text {a }}$ Ed. Rio de Janeiro, Editora Roca, 2016. p. 343344.

GIARDINO, R. et al. Electrochemotherapy: a novel approach to the treatment of metastatic nodules on the skin and subcutaneous tissues. Biomedical and Pharmacology Journal, v. 60, n. 8, p. 458-462, 2006.

MARTINS, M. et al. Eletroquimioterapia associada à nodulectomia para o tratamento de um sarcoma em cavidade oral de um cão - relato de caso. 2015. Disponível em: http://publicacoes.unifran.br/index.php/ investigacao/article/view/952. Acesso em: 15 jun. 2017.

MIR, L. M. et al. Effective treatment of cutaneous and subcutaneous malignant tumours by electrochemotherapy. British Journal of Cancer, v. 77, n. 12, p. 2336-2342, 1998.

MURPHY, S. Cutaneous squamous cell carcinoma in the cat: Current understanding and treatment approaches.

Journal of Feline Medicine and Surgery. v.15, n.5, p.4017, 2013.

OLIVEIRA, L. O. et al. Eletroterapia no tratamento do 
câncer. In: DALECK, C. R. et al. Oncologia em cães e gatos. São Paulo: Roca, 2009. p. 600-606.

PLASMEIJER, E. I. et al. Persistence of betapapillomavirus infections as a risk factor for actinic keratoses, precursor to cutaneous squamous. Cancer Research, v. 69, n. 23. p. 8926-8931. 2009.

SILVEIRA, L. M. G.; CUNHA, F. M.; BRUNNER C. H. M. Utilização de eletroquimioterapia para carcinoma de células escamosas tegumentar em felino. Pesquisa Veterinária Brasileira, v. 36, n. 4, p.297-302, 2016.

SPUGNINI, E. P. et al. Electroporation enhances bleomycin efficacy in cats with periocular carcinoma and advanced squamous cell carcinoma of the head. Journal of Veterinary Internal Medicine, v. 29, n. 5, p. 1368-1375, 2015.

THOMSON, M. Squamous cell carcinoma of the nasal planum in cats and dogs. Clinical Techniques in Small Animal Practice, v. 22, p.42-45, 2007.

UGEN, K.E.; HELLER, R. Electroporation as a method for the efficient in vivo delivery oftherapeutic genes. DNA Cell Biology, v. 22, p. 753, 2003.

Recebido em: 18.10 .2018 Aceito em: 20.10.2020 